\title{
Stent development and local drug delivery
}

\author{
E Regar, G Sianos and P W Serruys
}

Department of Cardiology, Thoraxcentre, Erasmus Medical Centre Rotterdam, The Netherlands

Correspondence to:

Prof. P W Serruys,

Thoraxcentre (Bd 406), Erasmus Medical Centre Rotterdam,

Dr Molewaterplein 40, 3015 GD Rotterdam, The Netherlands
Stent implantation has become the new standard angioplasty procedure. Instent re-stenosis remains the major limitation of coronary stenting. Re-stenosis is related to patient-, lesion- and procedure-specific factors.

Patient-specific factors can not be influenced to any extent. Procedure-specific factors are affected by implantation technique and stent characteristics. Design and material influence vascular injury and humoral and cellular response. Radiation has been shown to have inhibitory effects on smooth muscle cell growth and neo-intima formation, but in clinical trials the outcome has been hampered by re-stenosis at the edges of the radioactive stent ('candy wrapper').

New approaches target pharmacological modulation of local vascular biology by local administration of drugs. This allows for drug application at the precise site and time of vessel injury. Systemic release is minimal and this may reduce the risk of toxicity. The drug and the delivery vehicle must fulfil pharmacological, pharmacokinetic and mechanical requirements and the application of eluting degradable matrices seems to be a possible solution. Numerous pharmacological agents with antiproliferative properties are currently under clinical investigation, e.g. actinomycin D, rapamycin or paclitaxel. Another approach is for stents to be made of biodegradable materials as an alternative to metallic stents. Their potential long-term complications, such as in-stent restenosis and the inaccessibility of the lesion site for surgical revascularization, needs to be assessed.

Current investigational devices and the line of (pre)clinical investigation are discussed in detail. Currently, there is little experimental, and only preliminary clinical, understanding of the acute and long-term effects of drug-eluting or biodegradable stents in coronary arteries. The clinical benefit of these approaches still has to be proven.

Over the last decade, coronary stents have revolutionized the field of interventional cardiology. Stent implantation has become the new standard angioplasty procedure ${ }^{1-3}$. This popularity is mainly for two reasons: (i) the unique capability to master a major complication of balloon angioplasty - (sub)acute vessel closure; and (ii) a superior longterm outcome in comparison to balloon angioplasty ${ }^{4-8}$. The high reliability of the acute angioplasty result after stenting allowed for a dramatic expansion in the indication for catheter-based intervention 
(ostial lesions $^{9}$, bifurcation lesions ${ }^{10,11}$, left main lesions ${ }^{12,13}$, multiple lesions ${ }^{14}$ ).

In the early phase, device technology was directed toward improving the accessibility of lesions, e.g. in tortuous, small and/or calcified vessels. The advances included premounted stents, reduced crossing profile and improved flexibility. Modifications in stent design such as 'rotating' and 'locking' mechanisms afforded them high flexibility when unexpanded and remarkable radial strength when expanded. Further development included specifically configured stents for distinct indications, such as bifurcation lesions, lesions with side branch take-off, aneurysms and vessel rupture.

\section{The problem: re-stenosis}

As most acute aspects of stenting are resolved, the long-term outcome becomes more and more the focus of attention. In-stent re-stenosis remains for several reasons the major limitation of coronary stenting. The absolute number of in-stent re-stenotic lesions is increasing in parallel with the steadily increasing number of stenting procedures and with the complexity of culprit lesions. The treatment of in-stent restenosis is, despite progresses in radiation therapy, technically challenging and costly. In subsets of lesions (such as small vessel size and diffuse disease), an anticipated high risk for re-stenosis may prevent the use of stents.

Re-stenosis is considered as a local vascular manifestation of the general biological response to injury. Catheter-induced injury consists of denudation of the intima and stretching of the media. The wound-healing reaction consists in an inflammatory phase, a granulation phase and a remodelling phase. The inflammatory phase is characterized by platelets and growth factor activation, the granulation phase by smooth muscle cell and fibroblast migration and proliferation into the injured area, the remodelling phase by proteoglycan and collagen synthesis, which replaces early fibronectin as major component of extracellular matrix ${ }^{15}$. Current concepts describe three mechanisms of the re-stenotic process: early elastic recoil, late vessel remodelling and neo-intimal growth ${ }^{16,17}$. Coronary stents provide mechanical scaffolding that virtually eliminates recoil and remodelling ${ }^{18}$. However, neo-intimal growth continues to be a major problem.

Neo-intimal proliferation occurs principally, but not exclusively, at the site of the primary lesion within the first 6 months after stent implantation. Neo-intima is basically an accumulation of smooth muscle cells within a proteoglycan matrix that narrows the previously enlarged lumen. Neo-intima formation is triggered by a cascade of cellular and 
molecular events including platelet activation, leukocyte infiltration, smooth muscle cell expansion, extracellular matrix elaboration and reendothelialization.

In the clinical setting, neo-intimal formation and in-stent re-stenosis are related to patient-specific factors such as genetic predisposition or diabetes mellitus ${ }^{19}$, to lesion-specific factors such as vessel calibre ${ }^{20}$, lesion length or plaque burden ${ }^{21}$ and to procedure-specific factors such as extent of vessel damage, residual dissections ${ }^{22}$, number of stents, minimal stent diameter or minimal stent area ${ }^{23}$.

Patient-specific factors can not be influenced to any extent. Attempts to modulate lesion-specific factors by pharmacological therapy have not been not successful so far ${ }^{24,25}$. Procedure-specific factors may be favourably affected by the stent implantation technique and stent characteristics ${ }^{26}$.

\section{The solution: the ideal stent?}

From the interventionist's technical point of view, the ideal stent should have at least the following features:

- Reach any location within the coronary artery system

- Have a low profile, high trackability and flexibility

- Allow for precise placement with good visibility

- Guarantee predictable expansion with minimal foreshortening

- Provide equally distributed radial strength, be rigid and have many, thick struts

- Prevent plaque protrusion having many struts with small spaces between struts

- Allow for side-branch access having few struts with large spaces between struts

- Reduce acute thrombotic and inflammatory vessel response, i.e. have few, thin struts

- Allow wound healing but inhibit exaggerated neo-intimal growth. It should be thromboresistant and have high hydrodynamic compatibility

- Guarantee vessel accessibility for further intervention (PCR, bypass grafting) and thus possibly disappear after 6 months.

Unfortunately, all these requirements on stent characteristics are mutually incompatible.

\section{The ideal stent: small steps towards a big goal}

The focus of stent development in the first decade of stenting was on optimization of stent characteristics. Systematic investigations were performed to gain insights into mechanisms of stent action and vessel biology. This resulted in a huge variety of stents, differing in design, material, surface, radioactivity and coatings ${ }^{27}$. 


\section{Design}

Stent design varies in the geometry (number of intersections and interstrut area), in the strut configuration and the metal-to-artery ratio. These are the major determinants of stent profile, flexibility, radial strength and (elastic) expansion characteristics.

Presently, more than 55 stents are available (12 with FDA-approval) which are manufactured by more than 30 companies. They use two different expansion principles (balloon-expansion and self-expansion) and can be categorized in five basic design types: tubular, ring, multi-design, coil, and mesh.

The physical properties affect vascular injury and response. The different stent designs show a considerable range of the elastic moduli ${ }^{28}$ which affect stent expansion properties as late as 8 weeks after deployment ${ }^{29}$. Reduction of strut-strut intersections can reduce the vascular injury score, thrombosis and neo-intimal hyperplasia ${ }^{30}$. Non-uniform stent expansion increases vascular injury and in-stent re-stenosis ${ }^{31}$.

\section{Material and surface (texture)}

Stent materials and surface are relevant to in-stent re-stenosis. Surface characteristics can be modulated by (electromechanical) polishing, ion implantation or coating. Suitable stent materials are metals, metal-alloys or polymers. Chemistry, charge, and texture ${ }^{32}$ modulate humoral and

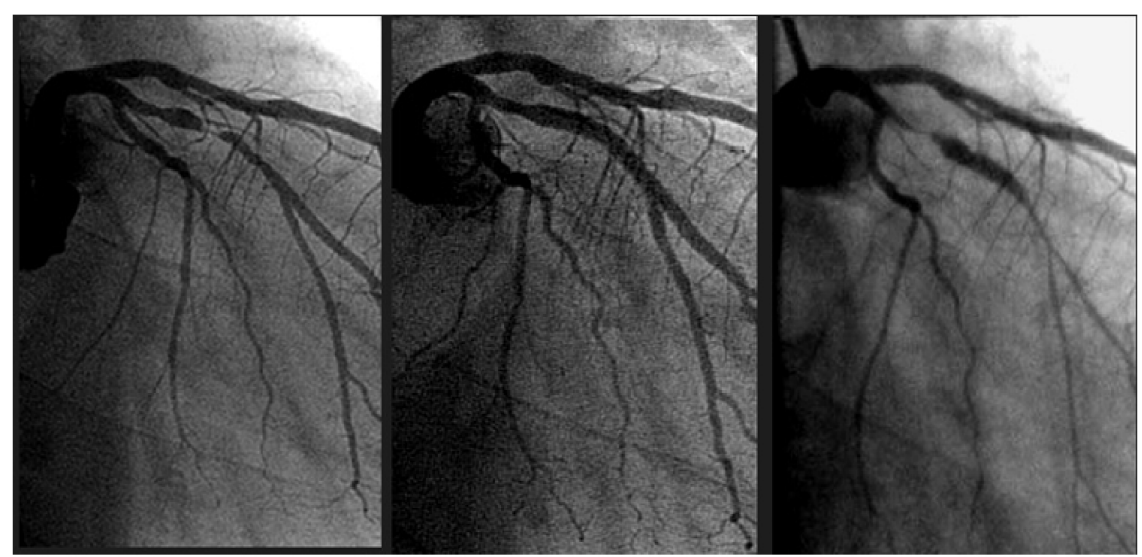

Fig. 1 Coronary angiogram of a the left coronary artery, showing a lesion of the circumflex artery pre-intervention (left), immediately after radioactive stent implantation (mid) and at 6-months' follow-up (right). At 6 months, there is significant narrowing at the proximal and at the distal edge of the radioactive stent ('candy wrapper' effect), while the lumen within the stent shows only minimal neo-intimal growths. 
Table 1 Results of [32P]-radioactive stents at 6-month follow-up

\begin{tabular}{lccccc}
\hline Study & $\begin{array}{c}\text { Patients } \\
(n)\end{array}$ & $\begin{array}{c}\text { Stent activity } \\
(\mu \mathrm{Cl})\end{array}$ & $\begin{array}{c}\text { Lesion length } \\
(\mathrm{mm})\end{array}$ & $\begin{array}{c}\text { Restenosis } \\
\text { rate }\end{array}$ & TLR \\
\hline IRIS 1A & 32 & $0.5-1.0$ & $<15$ & 31 & 21 \\
IRIS 1B & 25 & $0.75-1.5$ & $<15$ & 50 & 32 \\
IRIS Heidelberg & 11 & $1.5-3.0$ & $<15$ & 54 & N/A \\
IRIS Rotterdam & 26 & $0.75-1.5$ & $<28$ & 17 & 12 \\
[32P]-Dose response Rotterdam & 40 & $6.0-12$ & $<28$ & 44 & 25 \\
[32P]-Dose Response Milan & 23 & $0.75-3.0$ & $<28$ & 52 & 52 \\
& 29 & $3.0-6.0$ & & 41 & 41 \\
& 30 & $6.0-12$ & & 50 & 50 \\
& 40 & $12-21$ & & 30 & 30 \\
\hline
\end{tabular}

N/A, not available; TLR, target lesion revascularization.

cellular vessel response (plasma proteins, inflammatory and proliferative mediators, platelet and leukocyte activation). Copper is more frequently associated with subacute thrombosis than steel ${ }^{33}$.

\section{Radioactivity}

Another possible way to modify the physical properties is the introduction of radioactivity ${ }^{34,35}$. Radiation has proven inhibitory effects on smooth muscle cell growth and neo-intima formation ${ }^{36}$. However, clinical trials utilizing radioactive stents have been disappointing. Despite effective prevention of neo-intimal growth with the stent, clinical and angiographic outcomes have been hampered by re-stenosis at the edges of the radioactive stent; termed the 'candy wrapper' effect (Fig. 1) ) $^{37}$. This unfavourable phenomenon occurred irrespective of the stent design (cold end, hot end) or the dose rate (high activity versus low activity; Table 1).

\section{Coating}

Coating categories are various (Table 2 ). Stent coatings can dramatically reduce protein deposition and platelet adhesion in experimental settings (Fig. 2) ${ }^{38}$. However, polymers have shown conflicting results in the experimental setting ${ }^{39-41}$ with some provoking a severe tissue response ${ }^{42}$.

Table 2 Stent coating categories

$\begin{array}{ll}\begin{array}{l}\text { Inorganic/ceramic materials } \\ \text { Synthetic and biological polymers }\end{array} & \begin{array}{l}\text { Gold, si-carbide, diamond-like carbon, biogold } \\ \text { Phosphorylcholine, polyurethane, polyester, polylactic } \\ \text { acid, cellulose }\end{array} \\ \text { Human polymers } & \text { Chondroitin sulphate, hyaluronic acid, fibrin } \\ \text { Immobilized drugs } & \text { Heparin, paclitaxel, abciximab, P-15 (peptide) } \\ \text { Membrane-covered } & \text { PTFE, autologous vein and artery } \\ \text { Eluting, degradable matrices } & \end{array}$


Fig. 2 SEM of a heparin coated (left) and a non-coated stent.
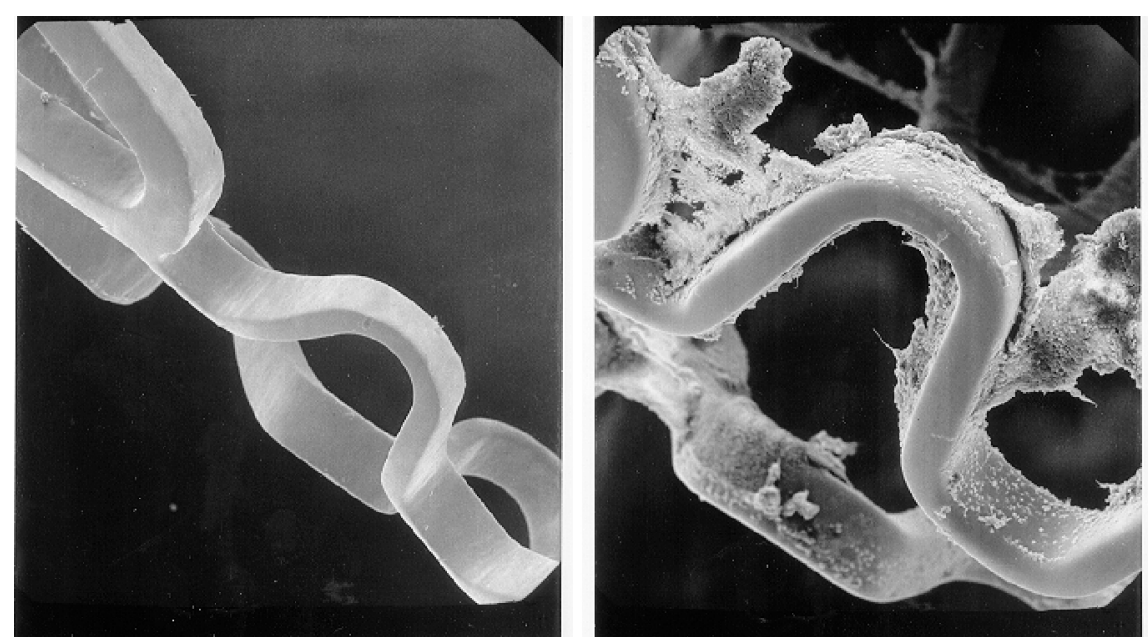

A number of other coatings like inert polymer ${ }^{30}$, phosphorylcholine ${ }^{43,44}$ or heparin ${ }^{45-47}$, demonstrated a reduction in (sub)acute stent thrombosis rate and possible effects on neo-intimal hyperplasia ${ }^{48}$.

In clinical practice, however, the acute beneficial effect on stent thrombosis is of minor relevance as already modern uncoated stents show a very low (sub)acute thrombosis rate. Furthermore, the acute beneficial effect did not result in a substantial decrease in in-stent re-stenosis ${ }^{49}$. In response to this, the interest in coatings has shifted towards considering coatings as vehicles for local drug delivery. So far, phosphorylcholine is the only clinically-available, polymer coated stent (Fig. 3) $)^{50}$.

\section{A big step: local drug delivery?}

New approaches target not only the stent characteristics but also the pharmacological modulation of the local vascular biology. A proposed

Fig. 3 Phosphorylcholine-coated stent (BiodivYsioTMTM SV stent; Biocompatibles Ltd, Surrey, UK).

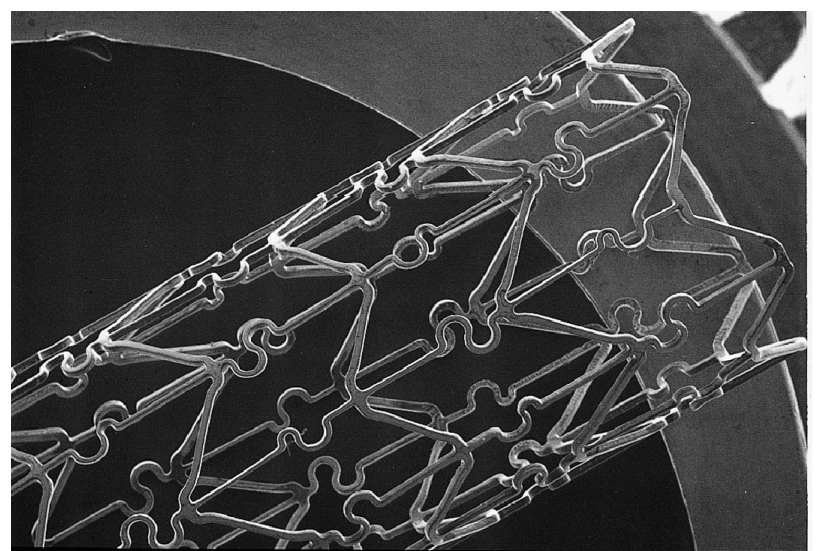


Fig. 4 SEM of a coated stent, showing the effect of stent expansion (left) and the effect of sterilization (right) on the coating.
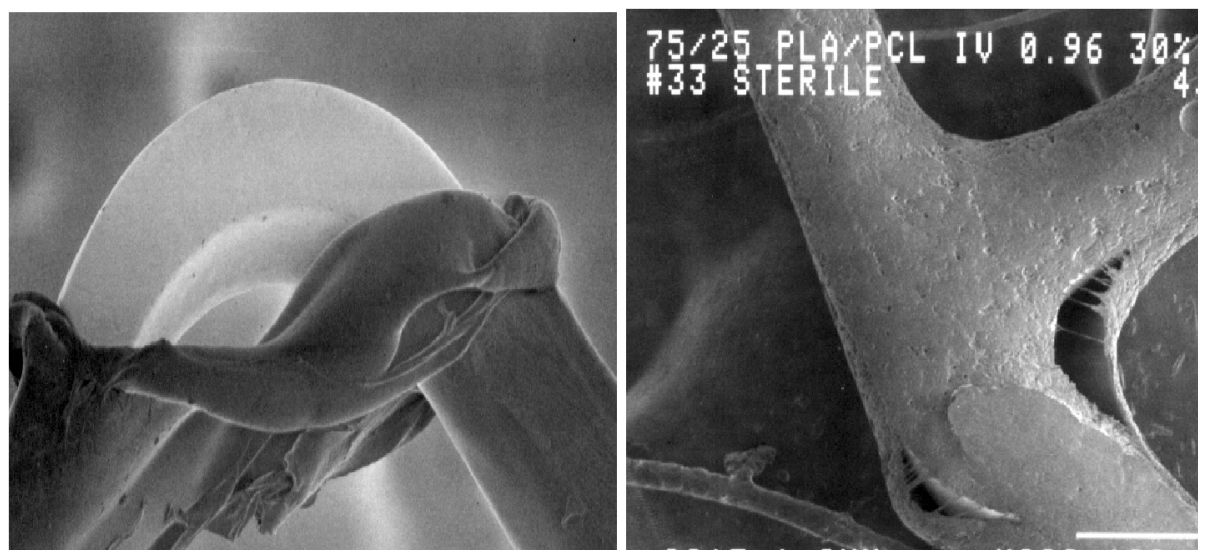

explanation for the repeated failure of clinical drug studies has been that agents given systemically cannot reach sufficient levels in injured arteries to impact significantly on the re-stenotic process. Local administration of drugs offers advantages. The active drug is applied to the vessel at the precise site and at the time of vessel injury. Local drug delivery might be able to achieve higher tissue concentrations of the drug. No additional materials or procedures are required. Systemic release is minimal and may reduce the risk of remote or systemic toxicity.

\section{Candidate delivery vehicles}

The delivery vehicle must fulfil pharmacological, pharmacokinetic and mechanical requirements. The release of the drug into the vessel must take place in a manner that is consistent with the drug's mode of action. Drug-release must be in predictable and controllable concentrations and within a known time span. The delivery vehicle must be suitable for sterilisation. It must follow the stent changes of configuration during stent expansion and resist mechanical injury caused by the implantation balloon. An example of possible deleterious effects of stent expansion and sterilisation on the coating is given in Figure 4. Currently, these problems are controlled, guaranteeing intact coating during clinical application (Fig. 5). The application of eluting, degradable matrices seems to be a possible solution. An overview of delivery vehicles for drug eluting systems is given in Table 3.

\section{Candidate drugs}

The drug should be able to inhibit the multiple components of the complex re-stenosis process. Uncontrolled neo-intima tissue accumulations shows 
Fig. 5 SEM of a contemporary coated and drug loaded stent. The integrity of the coating is not affected by stent expansion or sterilization.
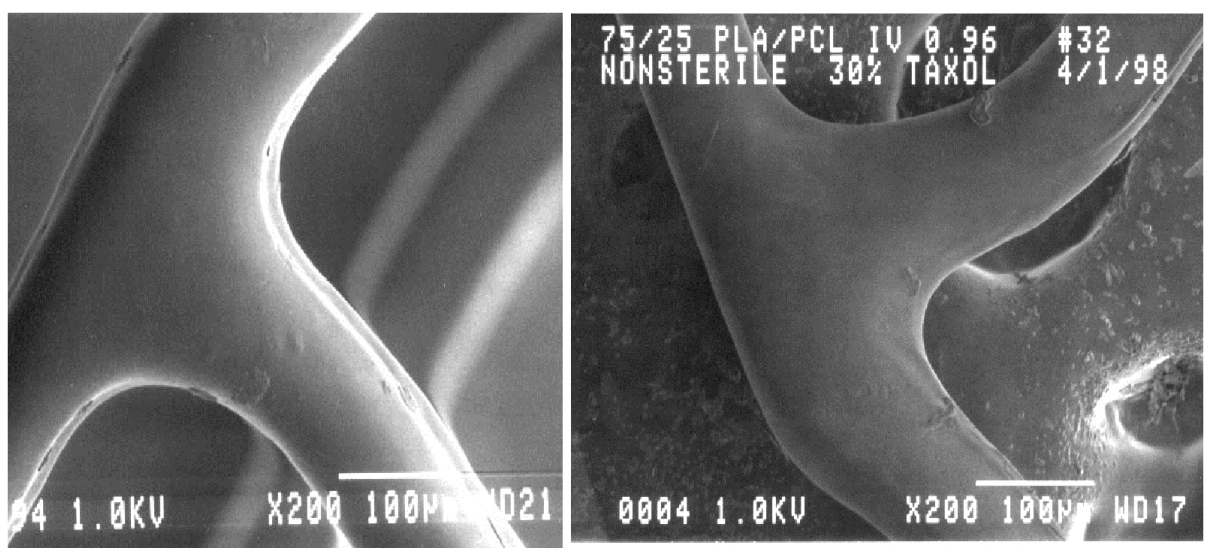

Table 3 Overview of drug delivery vehicles

\begin{tabular}{ll}
$*$ & Polyvinyl pyrolidone/cellulose esters \\
$*$ & Polyvinyl pyrolidone/polyurethane \\
$*$ & Polymethylidene maloleate \\
$*$ & Polylactide/glycoloide co-polymers \\
$*$ & Polyethylene glycol co-polymers \\
$*$ & Polyethylene vinyl alcohol \\
$*$ & Polydimethylsiloxane (silicone rubber) \\
\hline
\end{tabular}

some parallels to tumour growths; thus, the use of anti-tumour strategies seems to be a logical choice. Numerous pharmacological agents with antiproliferative properties have been tested for their potential to inhibit restenosis with mostly disappointing results ${ }^{51}$. Antimitotic compounds (like methotrexate and colchicine) have failed to inhibit smooth muscle cell proliferation and intimal thickening ${ }^{52,53}$. In contrast, other agents such as angiopeptin ${ }^{54}$, GP IIb/IIIa inhibitors or steroids ${ }^{55} 56$ have shown a promising inhibitory effect on neo-intimal proliferation. Potential candidates for local drug delivery are given in Table 4. The following drugs are now being tested in randomized clinical trials.

Table 4 Potential candidates for drug elution

\begin{tabular}{cc}
\hline Antineoplastic & Dexamethasone \\
Paclitaxel (TaxolTM) & Tacrolimus (FK506) \\
Taxol derivative (QP-2) & Collagen synthetase inhibitor \\
Actinomycin D & Halofuginone \\
Vincristine & Propyl hydroxylase \\
C-proteinase inhibitor & Metalloproteinase inhibitor \\
Antithrombins & \\
Hirudin and iloprost & \\
Heparin & AngiopeptinV \\
Immunosuppressants & VEGF \\
Sirolimus (Rapamycin & \\
Tranilast & \\
\hline
\end{tabular}




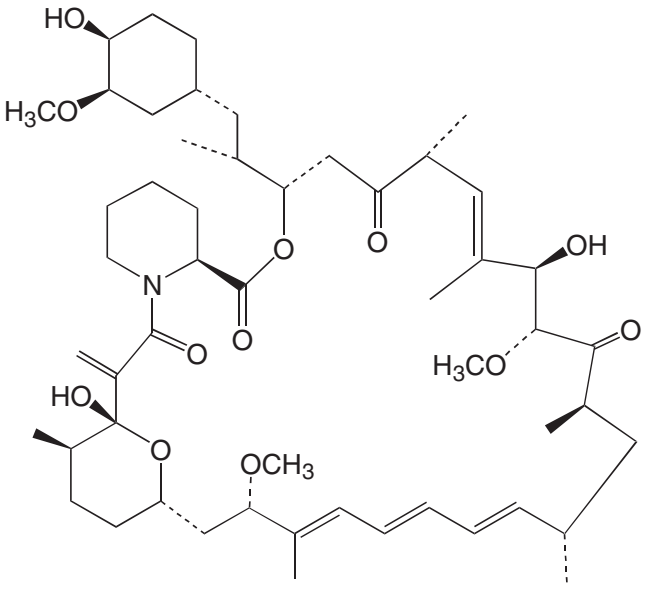

Fig. 6 Chemical structure of rapamycin (Sirolimus).

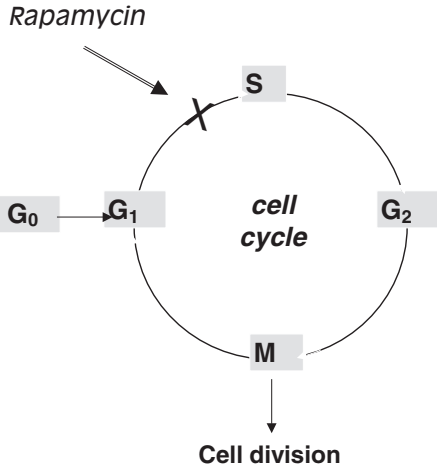

Fig. 7 Schematic of the mechanism of action of rapamycin within the cell cycle.

\section{Actinomycin D (Cosmegen $\left.{ }^{\oplus}\right)$}

Actinomycin D has been marketed world-wide since the 1960s. It is an antibiotic used for its antiproliferative properties in the treatment of various malignant neoplasmas (e.g. Wilms tumour, sarcomas, carcinoma of testis and uterus). It inhibits the proliferation of cells. Actinomycin D $\left(\mathrm{C}_{62} \mathrm{H}_{86} \mathrm{~N}_{12} \mathrm{O}_{16}\right)$ forms, via deoxyguanosine residues, a stable complex with double-stranded DNA and inhibits DNA-primed RNA synthesis.

\section{Rapamycin (Sirolimus; Rapamune $^{\oplus}$ )}

Rapamune $^{\circledR}$ is an FDA approved drug for the prophylaxis of renal transplant rejection in use since 1999. It is a naturally occurring macrocyclic lactone (Fig. 6) which is highly effective in preventing the onset and severity of disease in several animal models of autoimmune disease, such as insulin-dependent diabetes mellitus, systemic lupus erythematosus and arthritis.

The class of macrocyclic immunosuppressive agents (rapamycin, cyclosporin A, tacrolimus) bind to specific cytosolic proteins called immunophilins to gain their immunosuppressive activity. Rapamycin blocks G1 to $\mathrm{S}$ cell cycle progression (Fig. 7) by interacting with a specific target protein (mTOR, mammalian target of rapamycin) and inhibiting its activation. The inhibition of mTOR suppresses cytokine-driven (IL-2, IL-4, IL-7 and IL-15) T-cell proliferation.

mTOR is a key regulatory kinase and its inhibition has several important effects including: (i) inhibition of translation of a family of mRNAs that code for proteins essential for cell cycle progression; (ii) inhibition of IL-2induced transcription of proliferating cell nuclear antigen (PCNA) that is essential for DNA replication; (ii) blocking CD28-mediated sustained upregulation of IL-2 transcription in T cells; and (iv) inhibition of the kinase activity of the cdk4/cyclin D and cdk2/cyclin E complexes, essential for cell 
Fig. 8 The cell cycle: a functionally integrated cascade of positive and negative regulatory factors.

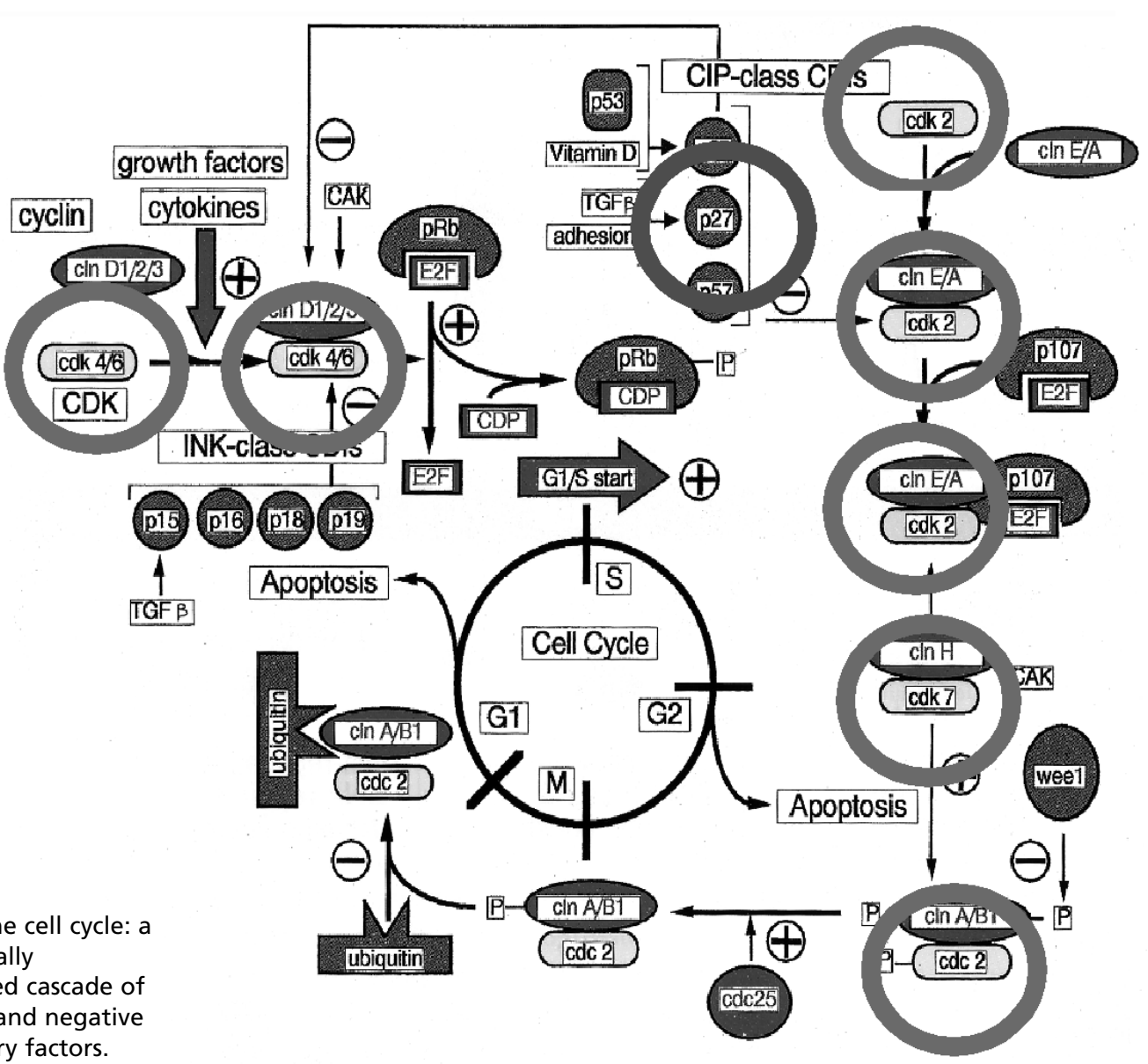

cycle progression. On overview of rapamycin effects within the cell cycle is given in Figure 8.

The mechanism of action is distinct from other immunosuppressive drugs that act solely by inhibiting DNA synthesis, such as mycophenolate mofetil (CellCept) and azathioprine (Imuran). Rapamycin is synergistic with cyclosporin A and has much lower toxicity than other immunosuppressive agents.

In in vitro and in vivo studies, rapamycin prevents proliferation of $\mathrm{T}$ cells but also proliferation ${ }^{57,58}$ and migration ${ }^{59}$ of smooth muscle cells. Furthermore, rapamycin has been shown to diminish smooth muscle cell hyperproliferation in several animal models of arteriopathy ${ }^{60-62}$.

\section{Paclitaxel (Taxol $\left.{ }^{\oplus}\right)$}

Paclitaxel was originally isolated from the bark of the Pacific Yew. It is an antineoplastic agent that is currently used to treat several types of cancer, most commonly breast and ovarian cancer. 
It is a diterpenoid with a characteristic taxane-skeleton of 20 carbon atoms and has a molecular weight of 853.9 Da. Paclitaxel exerts its pharmacological effects through formation of numerous decentralized and unorganized microtubules. This enhances the assembly of extraordinarily stable microtubules, interrupting proliferation, migration and signal transduction ${ }^{63,64}$ Unlike other antiproliferative agents of the colchicine type, which inhibit microtubuli assembly, paclitaxel shifts the microtubule equilibrium towards microtubule assembly. It is highly lipophylic, which promotes a rapid cellular uptake, and has a long-lasting effect in the cell due to the structural alteration of the cytoskeleton.

In vitro and in vivo studies have shown that paclitaxel may prevent or attenuate re-stenosis. Paclitaxel inhibits proliferation and migration of cultured smooth muscle cells in a dose-dependent manner ${ }^{65}$. In a rat balloon injury model, intraperitoneal administration of paclitaxel reduced neo-intimal area. In a rabbit atherosclerotic model where plaque burden was increased by electrical injury, local administration of paclitaxel reduced neo-intimal thickness ${ }^{66,67}$.

Investigational devices

Actinomycin D: Multi-Link Tetra ${ }^{\mathrm{TM}}$-D stent (Guidant, Santa Clara, CA, USA)

The stent is fabricated from medical 316L stainless steel tubing and is composed of a series of cylindrically oriented rings aligned along a common longitudinal axis. Each ring consists of 3 connecting bars and 6 expanding elements. The stent is premounted on a delivery catheter.

The antiproliferative drug is actinomycin D. The finished Multi-Link Tetra stent is coated with a polymer matrix (semicrystalline ethylene-vinyl alcohol co-polymer: EVAL) containing a maximal dose of $150 \mu \mathrm{g}$ actinomycin D. This is equivalent to 20-200 times less than the recommended total human adult dose of $500 \mu \mathrm{g} /$ day given intravenously for 5 days.

The delivery catheter is a rapid exchange design (0.014 inch guidewire). It is equipped with two radiopaque markers located underneath the balloon to mark the ends of the stent and has a 'stepped' balloon design to optimize stent and balloon shoulder configuration.

NIRX ${ }^{\text {TM }}$ - paclitaxel-coated conformer coronary stent (Boston Scientific, USA)

The stent is fabricated from medical 316LS stainless steel. The geometry is a continuous, uniform, multicellular design with adaptive cells capable of differential lengthening. This enables the stent to be flexible in the unexpanded configuration. Stent length is $15 \mathrm{~mm}$. The stent is premounted on a delivery catheter (Fig. 9).

The antiproliferative drug is paclitaxel. Paclitaxel is incorporated into a fast-release triblock co-polymer carrier system on the stent. There are two drug concentration. The 'low dose' concentration is $1.0 \mu \mathrm{g} / \mathrm{mm}^{2}$ 
Fig. $9 \mathrm{NIRx}^{\mathrm{TM}}$ Paclitaxel-coated conformer coronary stent (Boston Scientific, USA.

Fig. 10 Rapamycin coated BXTM VELOCITY stent (Cordis, Warren, USA).

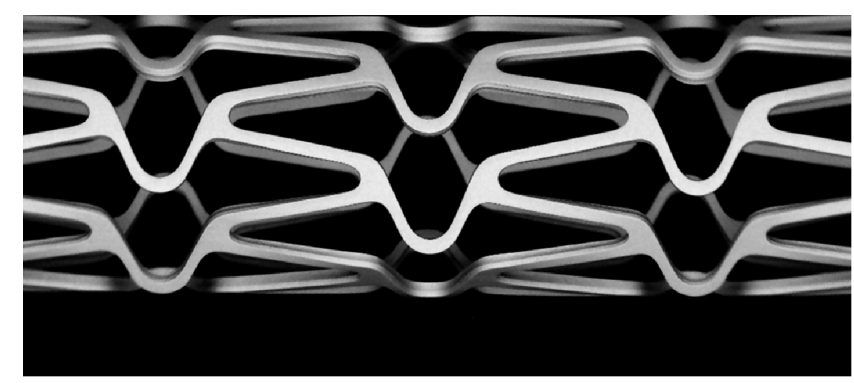

(loaded drug/stent surface area; total dose $85 \mu \mathrm{g}$ per stent) and gives sustained release over $\sim 28$ days. The 'moderate dose' is $2.0 \mu \mathrm{g} / \mathrm{mm}^{2}$ (loaded drug/stent surface area).and provides a rapid release in the first $24 \mathrm{~h}$, followed by a slower release over the following 28 days.

The delivery catheter is a monorail design $(0.014$ inch guidewire $/ 7 \mathrm{~F}$ guiding catheter). It is equipped with two radiopaque markers located underneath the balloon to mark the ends of the stent. The delivery balloon will be $3.0 \mathrm{~mm}$ and $3.5 \mathrm{~mm}$ in diameter.

\section{Rapamycin-coated BXTM VELOCITY stent (Cordis, Warren, USA)}

The stent is fabricated from medical 316LS stainless steel. It is available in 2 configurations: a 6-cell configuration (expanded diameter 2.5-3.25 $\mathrm{mm}$ ) and a 7-cell design (expanded diameter 3.5-3.75 mm). Stent length is $18 \mathrm{~mm}$. The stent is premounted on a delivery balloon with diameters of $2.5 \mathrm{~mm}, 3.0 \mathrm{~mm}$ and $3.5 \mathrm{~mm}$ (Fig. 10).

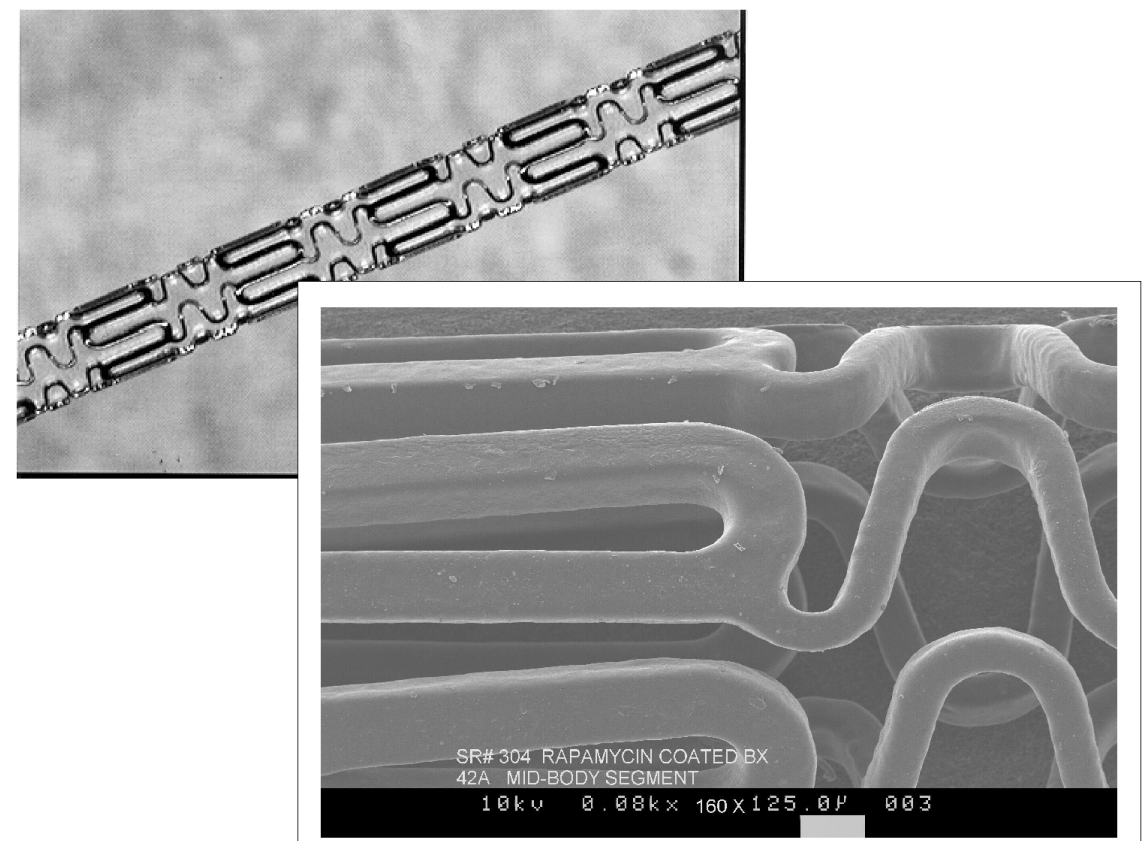

British Medical Bulletin 2001;59

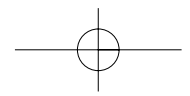


Fig. 11 Coating structure for fast drug release (left) and slow drug release (right).

\section{Clinical studies}
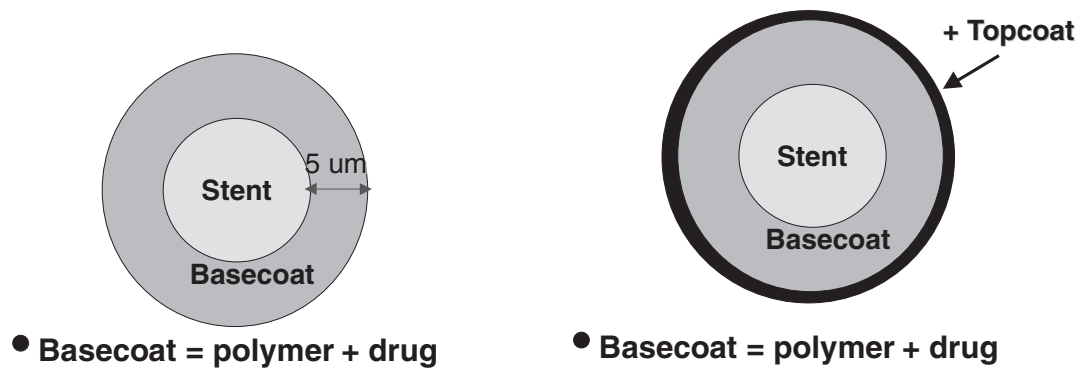

- Basecoat $=$ polymer + drug

- Topcoat $=\stackrel{+}{+}$ diffusion barrier

\section{Fast drug release}

\section{Slow drug release}

The antiproliferative drug is rapamycin. The stent contains $140 \mu \mathrm{g} / \mathrm{cm}^{2}$ which gives a total rapamycin content of $153 \mu \mathrm{g}$ on the 6-cell stent and 180 $\mu \mathrm{g}$ on the 7 -cell stent. The coating formulation consists of $30 \%$ rapamycin by weight in a 50:50 mixture of the polymers polyethylenevinylacetate (PEVA) and polybutylmethacrylate (PBMA; Fig. 11).

The delivery catheter utilizes a rapid exchange design $(0.014$ inch guidewire $/ 7 \mathrm{~F}$ guiding catheter). It is equipped with two radiopaque markers located underneath the balloon to mark the ends of the stent. The delivery balloon will be $3.0 \mathrm{~mm}$ and $3.5 \mathrm{~mm}$ in diameter.

\section{Actinomycin D}

There is no published research to date documenting the use of actinomycin $\mathrm{D}$ for treatment of coronary artery disease and/or restenosis. A phase 1, randomized clinical trial ACTION (ACTinomycin eluting stent Improves Outcomes by reducing Neointimal Hyperplasia) started in June 2001 to evaluate the safety and performance of the Multi-Link Tetra ${ }^{\mathrm{TM}}$-D stent system: 360 patients will be randomized to receive an actinomycin $\mathrm{D}$ coated stent or a non-coated stent for treatment of de novo lesions in native coronary arteries with a vessel calibre of 3.0-4.0 mm. Six month angiographic follow-up is expected to be completed in February 2002, 12-month clinical follow-up up is expected to be completed in August 2002.

\section{Rapamycin (Sirolimus)}

A first clinical application of the rapamycin-coated stents was performed in Sao Paulo and Rotterdam. Thirty patients with angina pectoris were electively treated with 2 different formulations of 
rapamycin-coated BX ${ }^{\mathrm{TM}}$ VELOCITY stents (Cordis) (slow release [SR], $n=15$, and fast release [FR], $n=15)$. All stents $(18 \mathrm{~mm})$ were successfully delivered, (3.0-3.5 $\mathrm{mm}$ vessel calibre) and patients were discharged without clinical complications. At 4 months angiographic and IVUS follow-up, there was minimal neo-intimal hyperplasia in both groups $(11.0 \pm 3.0 \%$ in the SR group and $10.4 \pm 3.0 \%$ in the FR group, $P=$ NS) by ultrasound and quantitative coronary angiography (in-stent late loss, $0.09 \pm 0.3 \mathrm{~mm}[\mathrm{SR}]$ and $-0.02 \pm 0.3 \mathrm{~mm}$ [FR]. No in-stent or edge re-stenosis was observed. No major clinical events (stent thrombosis, repeat revascularization, myocardial infarction, death) had occurred by 8 months ${ }^{68}$. At 1 year follow-up, IVUS volumetric analysis and angiography indicated minimal amounts of neo-intimal hyperplasia that were scarcely different from the 4 month data in both groups, with some patients showing no evidence of hyperplasia whatsoever. There were no MACE and no re-stenosis in either of the groups. One late acute MI occurred in the fast-release group at 14 months ${ }^{69}$.

The randomized RAVEL study with the rapamycin-coated $\mathrm{BX}^{\mathrm{TM}}$ VELOCITY balloon-expandable stent in the treatment of patients with de novo lesions in native coronary arteries is a multicenter, prospective, randomized double-blind clinical trial comparing bare metal and the drugcoated stents. A total of 220 patients were randomized for treatment with either a single rapamycin-coated $\left(140 \mu \mathrm{g} . \mathrm{cm}^{-2}\right)$ or a bare metal $\mathrm{BX} \mathrm{TM}^{\mathrm{TM}}$ VELOCITY stent. At 6-month follow-up, the restenosis rate of the treated group was zero, the loss in minimal lumen diameter was zero, there was no target lesion reintervention and the event-free survival was $96.5 \%{ }^{74}$.

The SIRIUS study is a multicentre, prospective, randomized doubleblind trial that is being conducted in 55 centres in the USA. Eleven hundred patients with focal de novo native coronary arterial lesions (2.5 to $3.5 \mathrm{~mm}$ diameter, 15 to $30 \mathrm{~mm}$ long) will be randomized for treatment with either rapamycin-coated $\left(109 \mathrm{mg} . \mathrm{cm}^{-2}\right)$ or bare metal BX $^{\mathrm{TM}}$ VELOCITY balloon expandable stents. The primary endpoints of the SIRIUS trial are target vessel failure (death, myocardial infarction, target lesion revascularization) at 9 months. In addition, secondary endpoints are core laboratory analysis of angiographic and intravascular ultrsound data to determine treatment effects on neointimal hyperplasia and in-stent restenosis. Clinical follow-up will continue for 3 years in order to assess late events. In addition to the pivotal RAVEL and SIRIUS trials, feasibility studies are ongoing to assess efficacy of rapamycincoated stents in more complex lesion subsets, such as in-stent restenosis.

\section{Paclitaxel}

There are several ongoing clinical trials of paclitaxel-coated stents. In the TAXUS I trial 61 patients were randomized to receive a paclitaxel-coated $\left(1.0 \mu \mathrm{g} / \mathrm{mm}^{2}\right)$ or a bare NIR stent. At 6-month follow-up, no restenosis 
was seen in the paclitaxel-coated stent group, while the restenosis rate in the bare stent group was $11 \%$. The late lumen loss of $0.35 \pm 0.47 \mathrm{~mm}$ was significantly lower in the paclitaxel-coated stent group $(0.71 \pm 0.88 \mathrm{~mm})$. The Asian ASPECT trial showed a clear dose response. Patients $(n=177)$ were randomized to receive a high dose $\left(3.1 \mu \mathrm{g} . \mathrm{mm}^{-2}\right)$ paclitaxel-coated, a low dose $\left(1.3 \mu \mathrm{g} . \mathrm{mm}^{-2}\right)$ paclitaxel-coated, or a bare stent. The restenosis rate at 6 months was $4 \%, 12 \%$, and $27 \%$, respectively ${ }^{75}$. The ongoing ELUTES trial randomises 180 patients into 5 groups -4 different dose levels and a bare stent control group.

In other clinical trials, the taxol derivate QP2 was used. The QP2 pilot study included 32 patients with de novo or restenosis lesions who underwent QuaDS-QP2 stent implantation. The stainless steel, slotted tube stent was 13 or $17 \mathrm{~mm}$ in length and coated with multiple ploymer sleeves that slowly release QP2 (up to $4000 \mu \mathrm{g}$ ). A 2-year follow-up of 25 patients recorded that they were all asymptomatic ${ }^{76}$. Another group reported on the 8 month IVUS follow-up. IVUS revealed only moderate neointima formation with a neointima burden of $13.6 \pm 14.9 \%{ }^{77}$. Another multicenter, trial randomized 266 patients to receive a QuaDS-QP2 stent (4000 mg with an elution over 180d) or a bare stent. Follow-up angiography at 6 months showed a significant reduction in restenosis in the QuaDS-QP2 stent group (6.9\% v. 36\%). However, this trial has been stopped by the safety committee because of an excessive adverse event rate in the QuaDS-QP2 stent group of $10.2 \%$ - periprocedural myocardial infarction and subacute stent thrombosis ${ }^{78}$.

\section{Another step: biodegradable stents}

Coronary stents exert their beneficial clinical effect within a relatively narrow time frame. Stent scaffolding is needed from the acute procedural phase (in case of threatened or actual vessel closure) until the first 6 months after the procedure to overcome late negative vessel remodelling. In the long-term perspective, metallic stents have potential complications such as in-stent re-stenosis and the inaccessibility of the lesion site for surgical revascularization. Thus stents made of biodegradable materials may be an ideal alternative.

\section{Experimental data}

The first requirement for polymeric materials in intracoronary stents is biocompatibility. In animal studies, the biocompatibility of polymer stents has been controversial suggesting that tissue incompatibility may be a major obstacle. 
Fig. 12 Poly-l-lactic monopolymer IgakiTamai biodegradable stent (Igaki Medical Planning Co, Ltd.

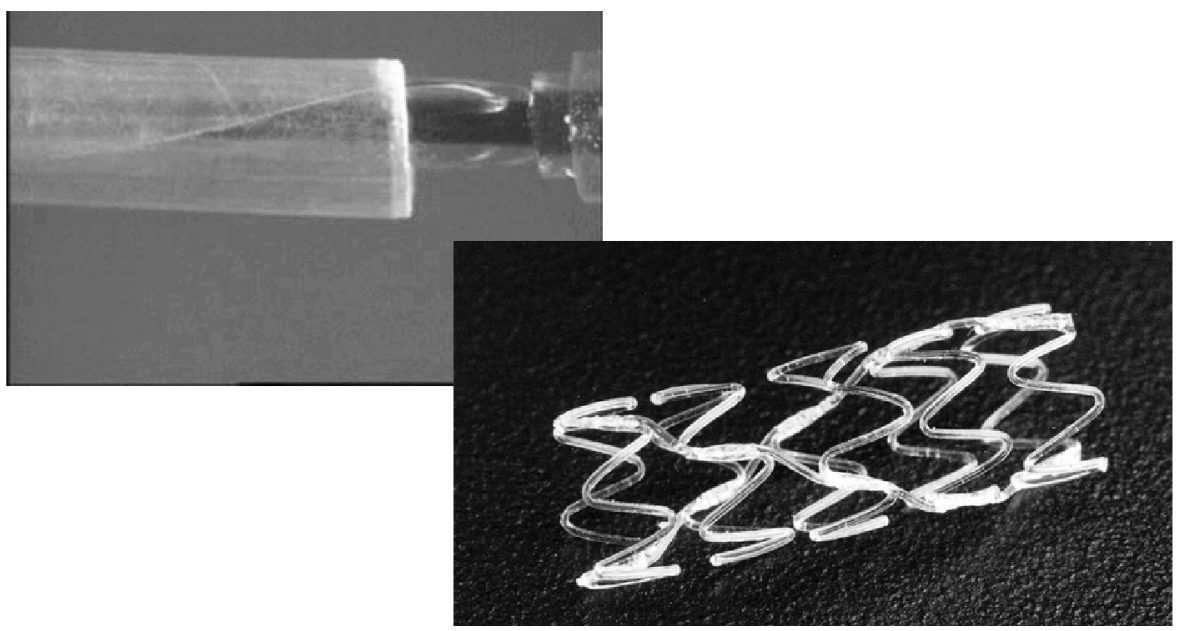

Marked inflammatory response after the implantation of 5 different polymer-loaded stents (polyglycolic acid/polylactic acid, polycaprolactone, polyhydroxybutyrate valerate, polyorthoester, and polyethyleneoxide/ polybutylene terephthalate) has been reported in a porcine coronary model $^{42}$. Thrombotic occlusion of polymeric stents was seen in other experiments ${ }^{70}$.

In contrast, Zidar et al reported only a minimal inflammatory reaction and minimal neo-intimal hyperplasia with the use of poly-l-lactic acid (PLLA) stents in canine femoral arteries. In vitro data revealed a reduced platelet adherence and thrombogenicity of the PLLA stent as compared with slotted-tube stainless steel metallic stents ${ }^{70}$.

\section{Investigational device: poly-l-lactic monopolymer Igaki-Tamai biodegradable stent (Igaki Medical Planning Co, Ltd)}

The Igaki-Tamai stent is a coil stent made of a poly-l-lactic (PLLA) monofilament (molecular mass, $183 \mathrm{kDa}$ ). PLLA has been used for orthopaedic applications in humans and has generally been found to be biocompatible. The stent is self-expanding with a zigzag helical design. The stent length is $12 \mathrm{~mm}$. The thickness of the stent strut is $0.17 \mathrm{~mm}$. In its expanded state, the stent covers $24 \%$ of the vessel area. The stent has a radiopaque gold marker at both ends of the prosthesis. Stents are mounted on standard angioplasty balloon catheters that are the same size as the stent with diameters of 3.0, 3.5, and $4.0 \mathrm{~mm}$ (Figure 12). It takes the stent 18-24 months to biodegrade fully.

Deployment of the stent is currently done with a balloon-expandable covered sheath system through an 8 French guiding catheter. The stent 
delivery balloon inflation is performed with a heated dye at $80^{\circ} \mathrm{C}$ using a $30 \mathrm{~s}$ inflation at 6-14 atm. This temperature ensures adequate stent expansion within $30 \mathrm{~s}$ and may minimize vessel injury caused by a heated balloon. The stent continues to expand gradually to its original size after deployment in vivo.

\section{Clinical data}

The first clinical data are available in 15 patients who underwent elective coronary PLLA Igaki-Tamai stent implantation: 25 stents were successfully implanted in 19 lesions. Angiographic success was achieved in all procedures. No stent thrombosis and no major cardiac event occurred within 30 days. Angiographically, both the re-stenosis rate and target lesion revascularization rate were $10.5 \%$ at 6 months. Intravascular ultrasound revealed no significant stent recoil at 1 day and stent expansion at follow-up. No major cardiac event, except for repeat angioplasty, developed within 6 months $^{71}$.

Long-term data (12 months) of 63 lesions in 50 patients have been previously presented. Angiographic analysis showed a good procedural result with was a $12 \pm 8 \%$ final diameter stenosis post-stent implantation. At 6 months, diameter stenosis was $38 \pm 23 \%$ and decreased slightly to 33 $\pm 23 \%$ at 12 months. Subacute thrombosis occurred in one patient at day 5 , but no other MI, urgent CABG, or death occurred over the 12 months $^{72}$.

\section{Limitations}

Although the principle of stent implantation is well established and although (most of) the applied drugs and polymers have been used in clinical practice for many years, there is little experimental and only preliminary clinical knowledge of the acute and long-term effects of drugeluting or biodegradable stents in coronary arteries. Thus, a number of concerns and open questions have to be investigated in the future.

The concerns include drug toxicity as well as acute and late vascular effects. A number of toxic effects are known for all drugs applied in cancer therapy such haematological toxicity (neutropenia), neurotoxicity (peripheral neuropathy), hypersensitivity reactions, or cardiac disturbances. However, these side-effects are described in patients undergoing high-dose chemotherapy for a malignant disease with plasma levels 100-1000 times higher (and over longer time periods) than plasma levels that result from a local delivery. Another concern is possible delayed wound healing and endothelialization. This would increase thrombogenicity and the danger of (late) stent thrombosis. 


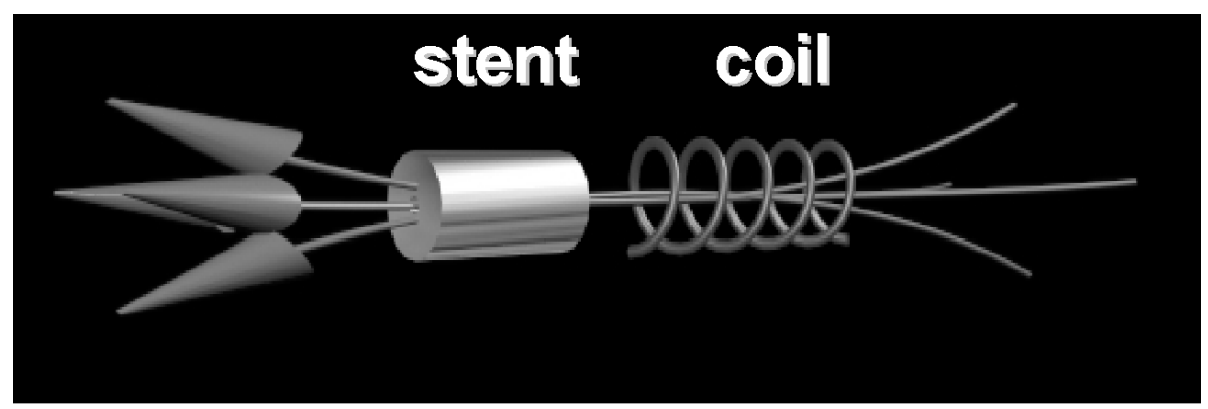

Fig. 13 Potential prevention of stent re-stenosis by non-invasively heating the stent, using alternating magnetic fields. High frequency alternating magnetic fields cause hysteresis phenomenon on the metallic stent, generating energy loss that appears as heat.

Further potential side-effects could be late positive remodelling and aneurysmal formation. Thus the most suitable antithrombotic regimen following drug-eluting and/or biodegradable stent implantation still has to be evaluated.

A series of open questions exists on the mechanism of action and also the design of local drug delivery systems and drug-eluting stents. Little is known of specific pharmacokinetic issues. There is a paucity of data on the most appropriate tissue concentration and the rate and duration of drug-release over time. The tissue concentration is dependent on close mechanical contact of the stent to the vascular tissue and on physiological transport forces into the tissue. Hydrophobic drugs, like paclitaxel, have greater variability in terms of drug delivery, while hydrophilic drugs, like heparin, have less variability and achieve higher local concentrations. Local concentrations and concentration gradients, however, are crucial parameters for biological effects. The relationship between vascular effects and physicochemical properties of the drugloaded stent is poorly understood. Drug distribution within the vessel wall seems to be significantly affected by the stent expansion pattern (uniform versus non-uniform) ${ }^{73}$.

\section{Conclusions and future perspectives}

Drug-eluting and biodegradable stents represent one of the fastest growing fields in interventional cardiology today. However, many unanswered questions still have to be resolved before determining the potential of these techniques. Hopefully, after the completion of planned and on-going trials many of these issues will be answered. Furthermore, these new technologies will have to prove effective in the daily routine of treating patients presenting with long lesions, small vessels, chronic 
occlusion, bifurcation, multi-vessel and/or left main stem disease or acute myocardial infarction.

Stent development will investigate a variety of possibilities to resolve the re-stenosis problem. Possibilities range from the further exploitation of different classes of drugs which are potential candidates for the inhibition of re-stenosis to the combination of biodegradability with drug delivery, local gene therapy (e.g. local expression of proliferation regulatory genes; transfer of cytotoxic genes, VEGF) or external heating of stents (Fig. 13).

\section{Acknowledgement}

ER was supported by a grant from the Deutsche Forschungsgemeinschaft.

\section{References}

1 Ruygrok PN, Ormiston JA, O’Shaughnessy B. Coronary angioplasty in New Zealand 1995-1998: a report from the National Coronary Angioplasty Registry. N Z Med J 2000; 113: 381-4

2 Ikeda S, Bosch J, Banz K, Schneller P. Economic outcomes analysis of stenting versus percutaneous transluminal coronary angioplasty for patients with coronary artery disease in Japan. J Invasive Cardiol 2000; 12: 194-9

3 Al Suwaidi J, Berger PB, Holmes DR. Coronary artery stents. JAMA 2000; 284: 1828-36

4 Serruys PW, de Jaegere P, Kiemeneij F et al. A comparison of balloon-expandable-stent implantation with balloon angioplasty in patients with coronary artery disease. Benestent Study Group [see comments]. N Engl J Med 1994; 331: 489-95

5 Fischman DL, Leon MB, Baim DS et al. A randomized comparison of coronary-stent placement and balloon angioplasty in the treatment of coronary artery disease. Stent Restenosis Study Investigators [see comments]. N Engl J Med 1994; 331: 496-501

6 Kimmel SE, Localio AR, Brensinger C et al. Effects of coronary stents on cardiovascular outcomes in broad-based clinical practice. Arch Intern Med 2000; 160: 2593-9

7 Angelini P, Vaughn WK, Zaqqa M, Wilson JM, Fish RD. Impact of the 'stent-when-feasible' policy on in-hospital and 6-month success and complication rates after coronary angioplasty: single-center experience with 17,956 revascularization procedures (1993-1997). Tex Heart Inst J 2000; 27: 337-45

8 Heuser R, Houser F, Culler SD et al. A retrospective study of 6,671 patients comparing coronary stenting and balloon angioplasty. J Invasive Cardiol 2000; 12: 354-62

9 Rocha-Singh K, Morris N, Wong SC, Schatz RA, Teirstein PS. Coronary stenting for treatment of ostial stenoses of native coronary arteries or aortocoronary saphenous venous grafts. Am J Cardiol 1995; 75: 26-9

10 Popma JJ, Lansky AJ, Ito S, Mintz GS, Leon MB. Contemporary stent designs: technical considerations, complications, role of intravascular ultrasound, and anticoagulation therapy. Prog Cardiovasc Dis 1996; 39: 111-28

11 Carlier SG, van der Giessen WJ, Foley DP et al. Stenting with a true bifurcated stent: acute and mid-term follow-up results. Cathet Cardiovasc Diagn 1999; 47: 361-96

12 Laham RJ, Carrozza JP, Baim DS. Treatment of unprotected left main stenoses with PalmazSchatz stenting. Cathet Cardiovasc Diagn 1996; 37: 77-80

13 Lopez JJ, Ho KK, Stoler RC et al. Percutaneous treatment of protected and unprotected left main coronary stenoses with new devices: immediate angiographic results and intermediateterm follow-up. J Am Coll Cardiol 1997; 29: 345-52 
14 Moussa I, Reimers B, Moses J et al. Long-term angiographic and clinical outcome of patients undergoing multivessel coronary stenting. Circulation 1997; 96: 3873-9

15 Forrester JS, Fishbein M, Helfant R, Fagin J. A paradigm for restenosis based on cell biology: clues for the development of new preventive therapies. J Am Coll Cardiol 1991; 17: 758-69

16 Lafont A, Guzman LA, Whitlow PL, Goormastic M, Cornhill JF, Chisolm GM. Restenosis after experimental angioplasty. Intimal, medial, and adventitial changes associated with constrictive remodeling. Circ Res 1995; 76: 996-1002

17 Schwartz RS, Topol EJ, Serruys PW, Sangiorgi G, Holmes Jr DR. Artery size, neointima, and remodeling: time for some standards. J Am Coll Cardiol 1998; 32: 2087-94

18 Mudra H, Regar E, Klauss V et al. Serial follow-up after optimized ultrasound-guided deployment of Palmaz- Schatz stents. In-stent neointimal proliferation without significant reference segment response. Circulation 1997; 95: 363-70

19 Sobel BE. Acceleration of restenosis by diabetes: pathogenetic implications. Circulation 2001; 103: $1185-7$

20 Mintz GS, Popma JJ, Pichard AD et al. Intravascular ultrasound predictors of restenosis after percutaneous transcatheter coronary revascularization. J Am Coll Cardiol 1996; 27: 1678-87

21 Prati F, Di Mario C, Moussa I et al. In-stent neointimal proliferation correlates with the amount of residual plaque burden outside the stent: an intravascular ultrasound study. Circulation 1999; 99: 1011-4

22 Kornowski R, Hong MK, Tio FO, Bramwell O, Wu H, Leon MB. In-stent restenosis: contributions of inflammatory responses and arterial injury to neointimal hyperplasia. J Am Coll Cardiol 1998; 31: 224-30

23 de Feyter PJ, Kay P, Disco C, Serruys PW. Reference chart derived from post-stent-implantation intravascular ultrasound predictors of 6-month expected restenosis on quantitative coronary angiography. Circulation 1999; 100: 1777-83

24 Lefkovits J, Topol EJ. Pharmacological approaches for the prevention of restenosis after percutaneous coronary intervention. Prog Cardiovasc Dis 1997; 40: 141-58

25 Rosanio S, Tocchi M, Patterson C, Runge MS. Prevention of restenosis after percutaneous coronary interventions: the medical approach. Thromb Haemost 1999; 82 (Suppl 1): 164-70

26 de Feyter PJ, Vos J, Rensing BJ. Anti-restenosis trials. Curr Interv Cardiol Rep 2000; 2: 326-31

27 Gunn J, Cumberland D. Does stent design influence restenosis? Eur Heart J 1999; 20: 1009-13

28 Lossef SV, Lutz RJ, Mundorf J, Barth KH. Comparison of mechanical deformation properties of metallic stents with use of stress-strain analysis. J Vasc Interv Radiol 1994; 5: 341-9

29 Hofma SH, Whelan DM, van Beusekom HM, Verdouw PD, van der Giessen WJ. Increasing arterial wall injury after long-term implantation of two types of stent in a porcine coronary model. Eur Heart J 1998; 19: 601-9

30 Rogers C, Edelman ER. Endovascular stent design dictates experimental restenosis and thrombosis. Circulation 1995; 91: 2995-3001

31 Carter AJ, Scott D, Rahdert D et al. Stent design favorably influences the vascular response in normal porcine coronary arteries. J Invasive Cardiol 1999; 11: 127-34

32 Edelman ER, Seifert P, Groothuis A, Morss A, Bornstein D, Rogers C. Gold-coated NIR stents in porcine coronary arteries. Circulation 2001; 103: 429-34

33 Wilczek KL, De Scheerder I, Wang K. Implantation of balloon expandable copper stents in porcine coronary arteries. A model for testing the efficacy of stent coating in decreasing stent thrombogenicity. Circulation 1995; 92 (Suppl): 455

34 Fischell TA, Hehrlein C. The radioisotope stent for the prevention of restenosis. Herz 1998; 23: 373-9

35 Carter AJ, Fischell TA. Current status of radioactive stents for the prevention of in-stent restenosis. Int J Radiat Oncol Biol Phys 1998; 41: 127-33

36 Rubin P, Williams JP, Riggs PN et al. Cellular and molecular mechanisms of radiation inhibition of restenosis. Part I: role of the macrophage and platelet-derived growth factor [see comments]. Int J Radiat Oncol Biol Phys 1998; 40: 929-41

37 Albiero R, Nishida T, Adamian $\mathrm{M}$ et al. Edge restenosis after implantation of high activity (32)P radioactive beta-emitting stents. Circulation 2000; 101: 2454-7

38 Simon C, Palmaz JC, Sprague EA. Protein interactions with endovascular prosthetic surfaces. J Long Term Eff Med Implants 2000; 10: 127-41 
39 van Beusekom HM, Serruys PW, van der Giessen WJ. Coronary stent coatings. Coron Artery Dis 1994; 5: 590-6

40 van Beusekom HM, Schwartz RS, van der Giessen WJ. Synthetic polymers. Semin Interv Cardiol 1998; 3: 145-8

41 van der Giessen WJ, Schwartz RS. Coated and active stents: an introduction. Semin Interv Cardiol 1998; 3: 125-6

42 van der Giessen WJ, Lincoff AM et al. Marked inflammatory sequelae to implantation of biodegradable and nonbiodegradable polymers in porcine coronary arteries. Circulation 1996; 94: 1690-7

43 Malik N, Gunn J, Shepherd L, Crossman DC, Cumberland DC, Holt CM. Phosphorylcholinecoated stents in porcine coronary arteries: in vivo assessment of biocompatibility. J Invasive Cardiol 2001; 13: 193-201

44 Whelan DM, van der Giessen WJ, Krabbendam SC et al. Biocompatibility of phosphorylcholine coated stents in normal porcine coronary arteries. Heart 2000; 83: 338-45

45 Serruys PW, Emanuelsson H, van der Giessen W et al. Heparin-coated Palmaz-Schatz stents in human coronary arteries. Early outcome of the Benestent-II Pilot Study. Circulation 1996; 93: 412-22

46 Ahn YK, Jeong MH, Kim JW et al. Preventive effects of the heparin-coated stent on restenosis in the porcine model. Cathet Cardiovasc Interv 1999; 48: 324-30

47 van der Giessen WJ, van Beusekom HM, Eijgelshoven MH, Morel MA, Serruys PW. Heparincoating of coronary stents. Semin Interv Cardiol 1998; 3: 173-6

48 Holmes DR, Camrud AR, Jorgenson MA, Edwards WD, Schwartz RS. Polymeric stenting in the porcine coronary artery model: differential outcome of exogenous fibrin sleeves versus polyurethane-coated stents. J Am Coll Cardiol 1994; 24: 525-31

49 Serruys PW, van Hout B, Bonnier H et al. Randomised comparison of implantation of heparincoated stents with balloon angioplasty in selected patients with coronary artery disease (Benestent II) [published erratum appears in Lancet 1998; 352: 1478]. Lancet 1998; 352: 673-81

50 Galli M, Bartorelli A, Bedogni F et al. Italian BiodivYsio open registry (BiodivYsio PC-coated stent): study of clinical outcomes of the implant of a PC-coated coronary stent. J Invasive Cardiol 2000; 12: 452-8

51 Mak KH, Topol EJ. Clinical trials to prevent restenosis after percutaneous coronary revascularization. Ann N Y Acad Sci 1997; 811: 255-84; discussion 284-8

52 O'Keefe JH, McCallister BD, Bateman TM, Kuhnlein DL, Ligon RW, Hartzler GO. Ineffectiveness of colchicine for the prevention of restenosis after coronary angioplasty. $\mathrm{J} A m$ Coll Cardiol 1992; 19: 1597-600

53 Muller DW, Topol EJ, Abrams GD, Gallagher KP, Ellis SG. Intramural methotrexate therapy for the prevention of neointimal thickening after balloon angioplasty. J Am Coll Cardiol 1992; 20: 460-6

54 De Scheerder I, Wilczek K, Van Dorpe J et al. Local angiopeptin delivery using coated stents reduces neointimal proliferation in overstretched porcine coronary arteries. I Invasive Cardiol 1996; 8: 215-22

55 de Scheerder I, Wang K, Wilczek K et al. Local methylprednisolone inhibition of foreign body response to coated intracoronary stents. Coron Artery Dis 1996; 7: 161-6

56 Lincoff AM, Furst JG, Ellis SG, Tuch RJ, Topol EJ. Sustained local delivery of dexamethasone by a novel intravascular eluting stent to prevent restenosis in the porcine coronary injury model. J Am Coll Cardiol 1997; 29: 808-16

57 Marx SO, Jayaraman T, Go LO, Marks AR. Rapamycin-FKBP inhibits cell cycle regulators of proliferation in vascular smooth muscle cells. Circ Res 1995; 76: 412-7

58 Mohacsi PJ, Tuller D, Hulliger B, Wijngaard PL. Different inhibitory effects of immunosuppressive drugs on human and rat aortic smooth muscle and endothelial cell proliferation stimulated by platelet-derived growth factor or endothelial cell growth factor. $J$ Heart Lung Transplant 1997; 16: 484-92

59 Poon M, Marx SO, Gallo R, Badimon JJ, Taubman MB, Marks AR. Rapamycin inhibits vascular smooth muscle cell migration. J Clin Invest 1996; 98: 2277-83 
60 Gregory CR, Huie P, Billingham ME, Morris RE. Rapamycin inhibits arterial intimal thickening caused by both alloimmune and mechanical injury. Its effect on cellular, growth factor, and cytokine response in injured vessels. Transplantation 1993; 55: 1409-18

61 Gregory CR, Huang X, Pratt RE et al. Treatment with rapamycin and mycophenolic acid reduces arterial intimal thickening produced by mechanical injury and allows endothelial replacement. Transplantation 1995; 59: 655-61

62 Poston RS, Billingham M, Hoyt EG et al. Rapamycin reverses chronic graft vascular disease in a novel cardiac allograft model. Circulation 1999; 100: 67-74

63 Schiff PB, Fant J, Horwitz SB. Promotion of microtubule assembly in vitro by taxol. Nature 1979; 277: 665-7

64 Rowinsky EK, Donehower RC. Paclitaxel (taxol). N Engl J Med 1995; 332: 1004-14

65 Sollott SJ, Cheng L, Pauly RR et al. Taxol inhibits neointimal smooth muscle cell accumulation after angioplasty in the rat. J Clin Invest 1995; 95: 1869-76

66 Axel DI, Kunert W, Goggelmann C et al. Paclitaxel inhibits arterial smooth muscle cell proliferation and migration in vitro and in vivo using local drug delivery. Circulation 1997; 96: 636-45

67 Herdeg C, Oberhoff M, Baumbach A et al. Local paclitaxel delivery for the prevention of restenosis: biological effects and efficacy in vivo. J Am Coll Cardiol 2000; 35: 1969-76

68 Sousa JE, Costa MA, Abizaid A et al. Lack of neointimal proliferation after implantation of Sirolimus-coated stents in human coronary arteries: a quantitative coronary angiography and three-dimensional intravascular ultrasound study. Circulation 2001; 103: 192-5

69 Sousa JEMR, Costa MA, Abizaid A et al. Mid- (4 months)and long-term (1 year) QCA and three-dimensional IVUS follow-up after implantation of Sirolimus-coated stent in human coronary arteries. J Am Coll Cardiol 2001; 37: 8A

70 Zidar J, Lincoff AM, Stack R. Biodegradable stents. In: Topol EJ. (ed) Textbook of Interventional Cardiology. Philadelphia, PA: WB Saunders, 1994; 787-802

71 Tamai H, Igaki K, Kyo E et al. Initial and 6-month results of biodegradable poly-l-lactic acid coronary stents in humans. Circulation 2000; 102: 399-404

72 Tsuji T, Tamai $\mathrm{H}$, Igaki $\mathrm{K}$ et al. One year follow-up of biodegradable self-expanding stent implantation in humans. J Am Coll Cardiol 2001; 37: 47A

73 Hwang CW, Wu D, Edelman ER. Stent-based delivery is associated with marked spatial variations in drug distribution. J Am Coll Cardiol 2001; 37: 1A

74 Morice M, Serruys P, Sousa J, Fajadet J, Perin M, Ben Hayashi E et al. The RAVEL study: a randomized study with the sirolimus-coated $\mathrm{BX}^{\mathrm{TM}}$ VELOCITY balloon-expandable stent in the treatment of patients with de novo native coronary artery lesions. Eur Heart J 2001: (Abstract)

75 The Asian paclitaxel eluting stent clinical trial. TCT. 2001; http://www.tetmd.com/ clinical-trials/breaking/one.html?presentation_id=261\&start_idx=1

76 de la Fuente LM, Miano J, Mrad J, Penazola E, Yeung AC, Eury R et al. Initial results of the Quanam drug eluting stent (QuaDS-QP2) registry (BARDDS) in human subjects. Cathet Cardiovasc Intervent 2001; 53: 480-8

77 Honda Y, Grube E, de la Fuente LM, Yock PG, Stertzer SH, Fitzgerald PJ. Novel drug-delivery stent: intravascular ultrasound observations from the first human experience with the QP2eluting polymer stent system. Circulation 2001; 104: 380-3

78 Liistro F, A C. Late acute thrombosis after paclitaxel eluting stent implantation. Heart 2001; 86: $262-4$ 